\title{
Synthesis of the $\mathrm{WC}-\mathrm{W}_{2} \mathrm{C}$ composite by electro-thermal explosion under pressure
}

\author{
V.T. Telepa ${ }^{\dagger}$, M.I. Alymov, V. A. Shcherbakov, A. V. Shcherbakov, V.I. Vershinnikov \\ ${ }^{\dagger}$ magnetic@ism.ac.ru
}

Merzhanov Institute of Structural Macrokinetics and Materials Science of RAS, 8 Osipyan str., Chernogolovka, 142432, Russia

The WC- $\mathrm{W}_{2} \mathrm{C}$ composite was synthesized by means of electro thermal explosion (ETE) under pressure. The method comprises preparing a mixture of tungsten and soot powders, cold pressing of the pellet and heating it with Joule heat until an exothermic synthesis reaction occurs under quasi-static compression conditions. Stimulation of the process by electric current makes it possible to synthesize the composite and to consolidate it to a minimum residual porosity. The purpose was to synthesize the WC- $\mathrm{W}_{2} \mathrm{C}$ composite by ETE processing of a tungsten and carbon black powders mixture under pressure. It was shown that in the synthesis the initial reagents were completely converted into the equilibrium final product containing $77.1 \mathrm{wt} \%$ of WC and 22.9 wt. $\%$ of $\mathrm{W}_{2} \mathrm{C}$. With increasing compression pressure up to $96 \mathrm{MPa}$, the maximum heating temperature of the target product by a combined heat source reached $3300 \mathrm{~K}$. This temperature was below the melting point of tungsten (3695 K) but above the melting point of the target product ( $\mathrm{WC}$ and $\mathrm{W}_{2} \mathrm{C}$ ). The microstructure formation of the $\mathrm{WC}_{-} \mathrm{W}_{2} \mathrm{C}$ composite prepared under the conditions of ETE was studied. It was shown that the composite contains $\mathrm{W}_{2} \mathrm{C}$ particles of needles. The length of the particles exceeds $10 \mu \mathrm{m}$, and their average thickness is $45-100 \mathrm{~nm}$. The $\mathrm{WC}-\mathrm{W}_{2} \mathrm{C}$ composite has a density of $12.5 \mathrm{~g} / \mathrm{cm}^{3}$ and Vickers microhardness of $16 \mathrm{GPa}$. The results obtained show that the ETE under pressure is promising for production of superhard composites.

Keywords: electrothermal explosion (ETE), ceramic composites, $\mathrm{W}_{2} \mathrm{C}, \mathrm{WC}$.

УДК: 536.46.621.762

\section{Синтез композита WC- $\mathrm{W}_{2} \mathrm{C}$ методом электротеплового взрыва под давлением}

\author{
Телепа В. Т. ${ }^{\dagger}$, Алымов М.И., Щербаков В. А., Щербаков А. В., Вершинников В.И. \\ Институт структурной макрокинетики и проблем материаловедения им. А.Г. Мержанова РАН, \\ ул. Академика Осипьяна, 8, Черноголовка, 142432, Россия
}

Методом электротеплового взрыва (ЭТВ) под давлением синтезирован композит WC-W 2 . Способ включает приготовление смеси порошков вольфрама и сажи, формование шихтовой заготовки и нагрев джоулевым теплом до осуществления экзотермической реакции синтеза в условиях квазиизостатического сжатия. Процесс подготовки и проведение ЭТВ занимает не более одной минуты. Стимулирование процесса электрическим током позволяет осуществить синтез композита и его консолидацию до минимальной остаточной пористости. Задачей исследования являлся поиск условий синтеза композита WC-W 2 С методом электротеплового взрыва смеси порошков вольфрама и углеродной сажи под давлением. В экспериментах шихтовые заготовки нагревали со скоростью 1300К/с при плот-

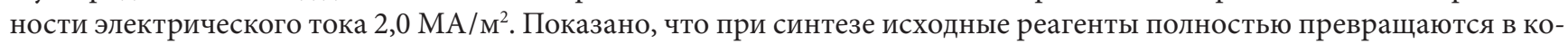
нечный продукт, содержащий 77,1 масс.\% WC и 22,9 масс.\% W $\mathrm{C}$, наличие свободного углерода составляло примерно $0,1 \div 0,08 \%$. При давлении сжатия 96 МПа максимальная температура нагрева целевого продукта комбинированным источником тепла (теплота экзотермической реакции и джоулевый нагрев) достигала 3300 К. Изучена микроструктура композита WC-W 2 , полученного в условиях ЭТВ. Показано, что композит содержит частицы W 2 С и WC пластинчатой формы, равномерно распределенные в объеме образца. Длина частиц превышает 10 мкм, а средняя толщина составляет $45 \div 100$ нм. Композит WC-W 2 С имеет плотность 12,5 г/см³ и микротвердость по Виккерсу 16 ГПа. Экспериментальные результаты показали, что ЭТВ под давлением является перспективным способом получения сверхтвердых композитов.

Ключевые слова: электротепловой взрыв (ЭТВ), керамический композит, $\mathrm{W}_{2} \mathrm{C}, \mathrm{WC}$. 


\section{1. Введение}

В рамках проведения работ по совершенствованию технологических процессов получения тугоплавких сверхтвердых веществ перспективно использовать энергетически эффективный и экологически чистый метод самораспространяющегося высокотемпературного синтеза (СВС) [1 -5]. Электротепловой взрыв (ЭТВ) является разновидностью СВС, в котором стимулирование экзотермической реакции синтеза осуществляется электрическим током [6-8]. Дополнительный источник нагрева позволяет расширить возможности СВС за счет использования химических систем с низким тепловым эффектом реакции. Например, синтез карбида вольфрама с использованием смеси порошков вольфрама и сажи в режиме СВС невозможно осуществить без дополнительного подогрева [6-8].

Целью настоящей работы является получение композита WC-W 2 методом электротеплового взрыва смеси порошков вольфрама и сажи в условиях квазиизостатического сжатия.

\section{2. Методика эксперимента}

В работе использовали смесь порошков вольфрама марки ПВН (размер частиц менее 25 мкм, удельная поверхность 5-10 м²/г) и сажи марки П804Т (дисперсностью менее 0,2 мкм, удельная поверхность $13-15 \mathrm{~m}^{2} /$ г). Содержание сажи в смеси составляло 6,10\% масс. (точность взвешивания $10^{-4}$ г). Выбор указанного количества углерода проводился исходя из стехиометрии WC, экспериментального подбора массы и многочисленных литературных данных. Для получения стехиометрического WC смесь теоретически должна содержать 6,12\% углерода. Литературные данные различных авторов предлагают содержание углерода 6,05-6,20\% масс. $[1,9,10]$.

Исходные порошки предварительно сушили в муфельной печи при температуре 450 К для удаления влаги. Смешение смеси проводили в шаровом барабане объемом 1 л в течение 4 часов при соотношении стальных шаров и шихты 10:1. Приготовленную смесь порошка вольфрама с углеродом после смешения взвешивали в необходимую массу и засыпали в пресс-форму. Синтез композита проводили на экспериментальной установке, описанной в $[12,13]$. Электропроводящим пуансоном установки сжимали порошок давлением 96 МПа и фиксировали его постоянным на весь период синтеза. Использование давления при ЭТВ позволяет обеспечить надежный контакт электрической цепи, проводить горячее прессование образца; формование изделий заданной формы с одновременным уплотнением. Использовали напряжение 10 В и плотность тока 2,0 MA/ ${ }^{2}$. Регулятор мощности тока позволяет, при необходимости, изменять плотность тока изменением напряжения.

Эксперимент проводился при следующих условиях: масса образца 20 г, давление в пресс-форме, установленное до начала нагрева реакционной смеси, 96 МПа, электрическое напряжение 10 В при мощности трансформатора 60 КВт. Проходящий электрический ток ини- циирует СВС процесс. Максимальная плотность тока,

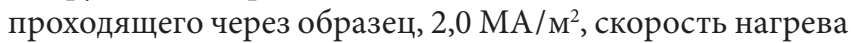
$1300 \mathrm{~K} / \mathrm{c}$. После выключения электрического тока прессформа с образцом остывала около 2 часов. Выбранное давление в 96 МПа обеспечивало: прессование образца в пресс-форме и получение замкнутой электрической цепи. Температуру в центре образца измеряли вольфрам-рениевой термопарой диаметром 100 мкм с частотой слежения 10 кГц.

Для дальнейшего исследования использовали шлифование и полирование образцов по стандартным методикам. Изучали поперечный разрез образцов. Микроструктуру полученных композитов исследовали с помощью растровой электронной микроскопии с использованием автоэмиссионного сканирующего электронного микроскопа сверхвысокого разрешения Zeiss Ultraplus A. Фазовый состав СВС-композитов изучали с помощью дифрактометра «ДРОН-3» с использованием монохроматического $\mathrm{Cu}-\mathrm{K}_{\alpha}$ излучения, компьютерной программы “CrystallographicaSearchMatch" и базы дифракционных данных PowerDiffractionFile (PDF-2, ICDD, USA, Release 2011). Микротвёрдость образцов по Виккерсу (HV) измеряли с помощью прибора ПМТ-3 в соответствии с ГОСТ 3450-76 при нагрузке 100 г и времени выдержки под нагрузкой 10 c [14]. Для каждого образца проводилось 5 измерений. Точность измерения микротвёрдости - 5\%. Плотность керамических образцов определяли методом гидростатического взвешивания по ГОСТ 25281-82 [15] на аналитических весах с точностью $10^{-4}$ г.

\section{3. Экспериментальные результаты и обсуждение}

В экспериментах реакционную смесь вольфрама и сажи нагревали со скоростью $1300 \mathrm{~K} /$. Максимальная температура образца, нагрев которого осуществлялся комбинированным источником, сочетающим химическое и электрическое тепловыделение, составляла $3300 \mathrm{~K}$. Эта температура ниже температуры плавления вольфрама $(3695$ K), но выше температуры плавления целевого продукта: WC - $3058 \mathrm{~K}, \mathrm{~W}_{2} \mathrm{C}-3008 \mathrm{~K}$. Время синтеза - 25 с. Время остывания на «воздухе» в прессформе - 2 часа.

Для определения минимального количества синтезируемой массы фазы $\mathrm{W}_{2} \mathrm{C}$ в конечном продукте проведен экспериментальный поиск процентного содержания углерода в реакционной смеси при одинаковых условиях синтеза. Получены образцы составом C-WC, WC-W 2 (до 50\% фазы $\mathrm{W}_{2} \mathrm{C}$ ), W-WC. Эксперименты проводились при давлениях 20 и 96 МПа. Точность измерения давления $-5 \%$.

На Рис. 1 представлены рентгенограммы композитов при давлении 96 МПа (603) и 20 МПа (605), синтезированных при одинаковых тепловых и технологических режимах: плотность тока, масса, скорость нагрева диаметр пуансона и т. д. Отличием двух экспериментов было содержание углерода в смеси: $603-6,10 \%, 605-6,17 \%$, фазовый состав $\mathrm{W}_{2} \mathrm{C}$ составлял $22,9 \%$ и $34,1 \%$, соответственно. Серия экспериментов позволила получить 
процентное содержание углерода в смеси (6,10\% масс.), при которой достигнута минимальная величина содержания фаз $\mathrm{W}_{2} \mathrm{C}$ в композите $\mathrm{WC}-\mathrm{W}_{2} \mathrm{C}$ (603). Из этого следует, что до величины 100 МПа давление на фазовый состав синтезируемого композита не влияет. Исходя из этих данных, в дальнейшем рассматриваются экспериментальные результаты 603.

По данным рентгенографического анализа композит 603 содержит 77,1\% масс. WC и 22,9\% масс. $\mathrm{W}_{2} \mathrm{C}$. Периоды решеток WC $(a=2,906 \mathrm{~A}, c=2,837 \mathrm{~A})$ и $\mathrm{W}_{2} \mathrm{C}$ $(a=2,999$ А, $c=4,731$ А) соответствуют литературным данным [9-11]. Расчетное содержание связанного углерода составляет: в фазе $\mathrm{WC}-4,703 \%, \mathrm{~W}_{2} \mathrm{C}-0,7236 \%$. Общее количество связанного углерода $-5,426 \%$, т.е. общий процент недостающего углерода составил $11 \%$. Состав синтезированного композита отличается от расчетного, так как вместо однофазного продукта - WC, на образование которого рассчитывался состав реакционной смеси, получен двухфазный продукт $\mathrm{WC}-\mathrm{W}_{2} \mathrm{C}$ - обусловлено недостатком углерода, часть углерода была израсходована на восстановление оксида вольфрама, присутствующего на поверхности частиц вольфрама и кислорода воздуха, находящегося в порах в исходной смеси. В композите 603 обнаружен не прореагировавший свободный углерод $0,08 \%$ масс. Таким образом, реакция синтеза прошла полностью, и получен равновесный состав композита $\mathrm{WC}-\mathrm{W}_{2} \mathrm{C}$.

На Рис. 2а представлена микроструктура и элементный состав керамического композита, полученного при давлении 96 МПа. Синтезированный композит имеют слоистую структуру, состоящую из пластинчатых частиц WC (светлые) и $\mathrm{W}_{2} \mathrm{C}$ (темные). Содержание фазы WC более высокое, чем $\mathrm{W}_{2} \mathrm{C}$, что согласуется с результатами рентгенофазового анализа. Частицы распределены в виде чередующихся слоев в объеме композита, длина их составляет $4 \div 10$ мкм, а толщина $-45 \div 100$ нм (Рис. 2b).

Измерение физико-механических характеристик показало, что керамический композит WC-W 2 , синтезированный при давлении $96 \mathrm{MПа,} \mathrm{консолидирован}$ до плотности 12,5 г $/ \mathrm{cm}^{3}$ и обладает средней микротвердостью 16 ГПа. Максимальная микротвердость композита достигает 21 ГПа, это соответствует микротвердости плавленого карбида вольфрама [8].

\section{4. Выводы}

Впервые методом электротеплового взрыва (ЭТВ) под давлением с использованием смеси порошков вольфрама и сажи синтезирован керамический композит WC-W C. Преимущество данного метода заключается в возможности одновременного осуществления синтеза и консолидации керамического композита. Показано, что полученный композит имеет слоистую микроструктуру, состоящую из чередующихся слоев WC и $\mathrm{W}_{2} \mathrm{C}$, имеющих толщину $45 \div 100$ нм. Определены физикомеханические характеристики полученного композита - плотность составляет 12,5 г/ см$^{3}$, а микротвердость по Виккерсу - 16 ГПа.

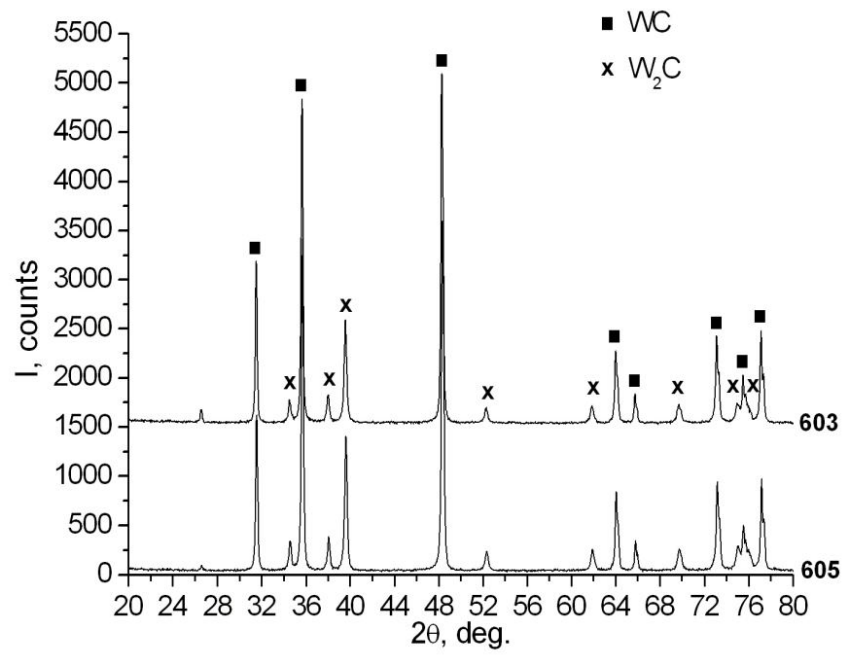

Рис. 1. Рентгенограмма композита $\mathrm{WC}-\mathrm{W}_{2} \mathrm{C}$, полученного при давлениях: $96 \mathrm{MПа} \mathrm{(603)} \mathrm{и} 20 \mathrm{MPa}$ (605).

Fig. 1. $\mathrm{XRD}$ of the $\mathrm{WC}-\mathrm{W}_{2} \mathrm{C}$ ceramic composite obtained at $P=96 \mathrm{MPa}$ (603) and $20 \mathrm{MPa}^{2}(605)$.

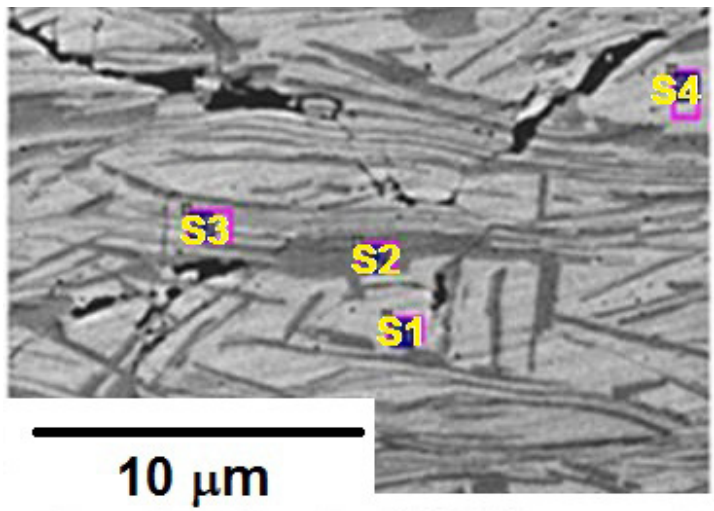

\begin{tabular}{|c|c|c|c|}
\hline & $\mathrm{C}$ & $\mathrm{W}$ & \\
\hline S1 & 6.16 & 93.84 & $\mathrm{WC}$ \\
\hline S2 & 8.20 & 91.80 & $\mathrm{~W}_{2} \mathrm{C}$ \\
\hline S3 & 6.26 & 93.74 & $\mathrm{~W}_{2} \mathrm{C}$ \\
\hline S4 & 6.11 & 93.89 & $\mathrm{WC}$ \\
\hline
\end{tabular}

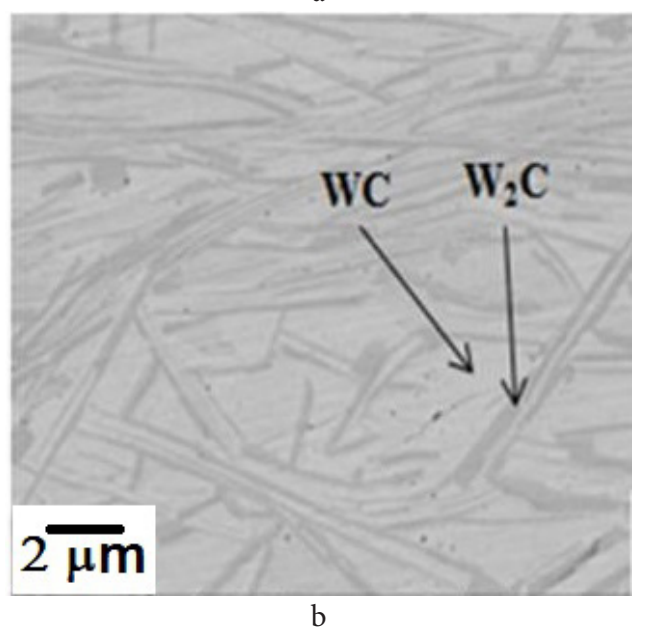

Рис. 2. Микроструктура и химический состав керамики $\mathrm{WC}-\mathrm{W}_{2} \mathrm{C}$.

Fig. 2. SEM images and EDS results for $\mathrm{WC}-\mathrm{W}_{2} \mathrm{C}$ ceramic. 


\section{Литература/References}

1. A.G. Merzhanov. Combustion processes and synthesis of materials. Chernogolovka, ISMAN (1998) 511 p. (in Russian) [А. Г. Мержанов. Процессы горения и синтез материалов. Черноголовка, ИСМАН (1998) 511 с.]

2. V.I. Yukhvid, V. A. Gorshkov, V. N. Borsh, P. A. Miloserdov, N. V. Sachkova, M. I. Alymov. Letters on Materials. 7(3), 332 (2017). (in Russian) [В.И. Юхвид, В.А. Горшков, В.Н. Борщ, П.А. Милосердов, Н.В. Сачкова, М. И. Алымов. Письма о материалах. 7(3), 332 (2017).] DOI: $10.22226 / 2410-3535-2017-3-332-336$

3. A.S. Shchukin, A.E. Sytschev. Letters on Materials. 7(3), 244 (2017). (in Russian) [A.C. Щукин, А.Е. Сычев. Письма о материалах. 7(3), 244 (2017).] DOI: $10.22226 / 2410-3535-2017-3-244-248$

4. A.S. Ustyukhin, A.V. Ankudinov, V.A. Zelenskiy, I.M. Milyaev, M.I. Alymov. Letters on Materials. 7(3), 249 (2017). (in Russian) [A.С. Устюхин, А.В. Анкудинов, В.А. Зеленский, И.М. Миляев, М. И. Алымов. Письма о материалах. 7(3), 249 (2017).] DOI: $10.22226 / 2410-3535-2017-3-249-253$

5. I. V. Saikov, M.I. Alymov, S. G. Vadchenko, I. D. Kovalev. Letters on Materials. 7(4), 465 (2017). (in Russian) [И.В. Сайков, М.И. Алымов, С.Г. Вадченко, И. Д. Ковалев. Письма о материалах. 7(4), 465 (2017).] DOI: 10.22226/2410-3535-2017-4-465-468

6. V.T. Telepa, V.A. Shcherbakov, A.V. Shcherbakov. Letters on Materials. 6(4), 286 (2016). (in Russian) [В.Т. Телепа, В.А. Щербаков, А. В. Щербаков. $\begin{array}{lllll}\text { Письма о материалах. 6(4), } 286 & \text { (2016).] }\end{array}$ DOI: $10.22226 / 2410-3535-2016-4-286-289$

7. V.A. Shcherbakov, A.N. Gryadunov, M.I. Alymov, N. V. Sachkova. Letters on Materials. 6(3), 217 (2016). (in Russian) [В. А.Щербаков, А. Н.Грядунов, М. И. Алымов, Н. В. Сачкова. Письма о материалах. 6(3), 217 (2016).] DOI: $10.22226 / 2410-3535-2016-3-217-220$
8. V.A. Shcherbakov, A.N. Gryadunov, M.I. Alymov. Letters on Materials. 7(4), 398 (2017). (in Russian) [В.А. Щербаков, А.Н. Грядунов, М.И. Алымов. $\begin{array}{lllll}\text { Письма о материалах. } & 7(4), & 398 & \text { (2017).] }\end{array}$ DOI: 10.22226/2410-3535-2017-4-398-401

9. A. S. Kurlov, I. A. Gusev. Advances in Chemistry. 75(7), 687 (2006). (in Russian) [А.С. Курлов, И.А. Гусев. Успехи химии. 75(7), 687 (2006).] DOI: 10.1002/chin.200701226

10. G.V. Samsonov, V.K. Vitryanyuk, F.I. Chaplygin. Carbidy volframa (Tungsten Carbides). Kiev, Naukova Dumka (1974) 176 p. (inRussian) [Г.В. Самсонов, В.К. Витрянюк, Ф.И. Чаплыгин. Карбиды вольфрама. Киев, Наукова думка (1974) 176 с.]

11. I.P. Borovinskaya, T.I. Ignatieva, V.I. Vershinnikov, O. M. Miloserdova, V. N. Semenova. Powder metallurgy. (9-10), 3 (2008). (in Russian) [И.П. Боровинская, Т.И.Игнатьева, В.И. Вершинников, О. М.Милосердова, В.Н. Семенова. Порошковая металлургия. (9-10), 3 (2008).] DOI: 10.1007/s11106-008-9051-1

12. V.A. Shcherbakov, V.T. Telepa, A.V. Shcherbakov. Compos. Nanostr. 9(1), 70 (2016) (in Russian) [В.А. Щербаков, В.Т. Телепа, А.В. Щербаков. Композиты и наноструктуры. 9(1), 70 (2016).]

13. V.A. Shcherbakov, V.T. Telepa, A. V. Shcherbakov. Jnt. J. of Self-Propag High-Temp. Synth. 24(4), 251 (2015). (in Russian) [В. А. Щербаков, В. Т. Телепа, А. В. Щербаков. Международный журнал Самораспространяющийся высокотемпературный синтез. 24(4), 251 (2015).] DOI: $10.3103 / \mathrm{S} 1061386215040111$

14. GOST R ISO 6507-1 2007. Metals and alloys. Hardness testing Vickers. (in Russian) [ГОСТ Р ИСО 6507-1 -2007. Металлы и сплавы. Измерение твердости по Виккерсу.]

15. GOST 25281-82. Powder metallurgy. Method of determination of formings density. (in Russian) [ГОСТ 25281-82. Металлургия порошковая. Методы определения плотности формовок.] 